\title{
Genomics in cardiovascular diseases: analysis of the importance of the toll-like receptor signaling pathway
}

This article was published in the following Dove Press journal:

International Journal of General Medicine

24 October 2012

Number of times this article has been viewed

\author{
J Bustamante' \\ E Tamayo ${ }^{2}$ \\ J Herreros ${ }^{3,4}$ \\ 'Department of Cardiovascular \\ Surgery, Hospital Universitario La \\ Princesa, Madrid, 'Department of \\ Anesthesiology and Intensive Care, \\ Hospital Clinico Universitario de \\ Valladolid, Valladolid, ${ }^{3}$ Department \\ of Cardiovascular Surgery, Hospital \\ Universitario Valdecilla, Santander, \\ ${ }^{4}$ Biomedical Engineering Institute of \\ Santander, Santander, Spain
}

\begin{abstract}
The development of techniques for genomics study makes it possible for us to further our knowledge about the physiopathology of various immunological or infectious diseases. These techniques improve our understanding of the development and evolution of such diseases, including those of cardiovascular origin, whilst they help to bring about the design of new therapeutic strategies. We are reviewing the genetic alterations of immunity in said field, and focusing on the signaling pathway of toll-like receptors because not only does this play a decisive role in response to microorganisms, it is also heavily involved in modulating the inflammatory response to tissue damage, a side effect of numerous cardiovascular diseases. These alterations in tissue homeostasis are present under a wide range of circumstances, such as reperfusion ischemia (myocardial infarction) phenomena, arteriosclerosis, or valvulopathy.
\end{abstract}

Keywords: genome-wide association study, single-nucleotide polymorphism, innate immune system, ischemic/reperfusion, myocardial infarction

\section{Introduction}

Recent advances in molecular biology have increased our knowledge of how genes control physiological functions involved in the modulation of specific phenotypes. The ability to interrogate the entire genome was made possible by two key advances: the Human Genome Project, with a draft sequence in 2001, and a nearly-complete sequence in 2003, and the International HapMap project. ${ }^{1-4}$

The human genome consists of approximately 25,000 genes codified by approximately 3.1 billion base pairs, distributed in 23 pairs of chromosomes. ${ }^{5}$ When DNA is sequenced, an inter-individual variability in nucleotide sequences can be detected. Differences in single bases are by far the most common example of genetic variation, known as single-nucleotide polymorphisms (SNPs). A SNP is a single nucleotide DNA sequence variant in the genome that differs between members of the same species or a pair of chromosomes in an individual. SNPs occur on average every 300 base pairs. Hundreds of thousands of SNPs have been discovered and are available in public databases. ${ }^{6}$ Comparing DNA sequences of two unrelated individuals has shown the existence of, on average, approximately one difference at every 1,200 bases.

After years in which there were reports of only isolated data and occasional associations of genes with specific pathologies, we have come to a point where highthroughput technologies (which genotype more than 500,000 genetic markers known as SNPs) and novel statistical tools have led to a virtual explosion of novel genetic markers associated with complex human diseases. 
SNP assay can become a method of analysis that makes it possible to explain the genesis of specific pathologies, and to define the underlying patterns of inheriting genetic variation. The inheritance pattern is quantified by the linkage disequilibrium, which represents the likelihood that alleles of nearby SNPs will stay together and retain their linear arrangement on a haplotype during meiosis. This likelihood depends on the mechanisms of recombination as well as their frequency, it being more frequent among alleles less separated in the genome. Once these mechanisms are known, researchers should analyze subsets of SNPs (called tag SNPs) to design genotyping arrays, and be able to perform association studies. Genetic variants that are not directly genotyped can then be imputed from the genotyped tag-SNP subset. Imputation presumes the SNP allele at a different location, inferred by its degree of linkage disequilibrium with an allele at a directly genotyped variant. ${ }^{7}$

Knowledge about genes and SNP functions is essential for establishing the scientific basis for how genes interact with the environment and produce a specific phenotype. However, while analyzing genetic variations and their association with diseases is relatively simple, final confirmation of their functional importance is normally more complex. Precisely for that reason, one of the groups of biomarkers being intensely studied, is that of the genetic variants. ${ }^{8}$

Our review attempts to update, and show the evolution that the development of knowledge about the genetic alterations that affect the immune system has undergone in the last years. We are specifically going to analyse the role of the signaling pathway for toll-like receptors (TLRs). ${ }^{9}{ }^{10}$ These receptors and their alteration have been implicated in the genesis of some the most currently relevant cardiovascular pathologies, given their function as immune-regulators that regulate determined signaling pathways. Their regulation is extremely complex. Understand ing the regulation of signaling pathways is of great importance since it permits us a better understanding of the physiopathology of the diseases, and will allow for a better therapeutical targeting of disease in the future via blockage of specific signaling pathways. ${ }^{11}$

\section{Genome-wide association studies}

Recently, genome-wide association studies (GWAS) have made it possible to analyze new loci associated with various diseases such as, rheumatoid arthritis, Crohn's disease, Type 2 diabetes, bipolar disorder, and other pathologies included in GWAS catalog. ${ }^{12}$ These studies are based on the genetic analysis of very large case samples and controls, by genotyping thousands of SNPs using DNA microchips.
The results of the HapMap project on genotype frequencies and haplotype structure make it possible to select the minimum SNPs required in GWAS genotyping, in order to make the detection of the majority of the shared genetic variability existing in the human genome possible. ${ }^{13}$

The advantages of GWAS over genetic studies of cases and controls, lie in the availability of greater sample sizes. Automated genotyping of the SNPs in the entire genome (consequently, not restricted to candidate genes) improves the quality of the analysis. In addition, GWAS perform a SNP quality control, given that they exclude SNPs from the analysis when the Hardy-Weinberg equilibrium is not met, when an allele frequency is $<1 \%$, or when the genotyping success rate is $<80 \%-90 \%$. The SNPs are selected on the basis of ability to reproduce the results in other populations in order for them to be considered significant. ${ }^{13,14}$

Limitations of these studies are that: (1) it is difficult to detect loci of small effect; (2) there is preferential selection of SNPs so that other polymorphisms, such as copy number variation and microsatellites, are not analyzed; (3) the contribution of low-frequency SNPs is not evaluated; and (4) they are generally performed using caucasian individuals and other population groups have not been analyzed.

\section{Innate immune system}

The innate immune system is the first line of defense against external damaging agents. It is also known to intervene in inflammatory-induced phenomena, such as those produced by the activation that tissue damage or ischemia-reperfusion (I/R) injury generates in tissue. ${ }^{15}$

Within the immune system, TLRs are a crucial link between the pathogen-associated molecular patterns and membrane-bound CD14, causing intracellular signaling with the translocation of the regulatory transcription nuclear factor

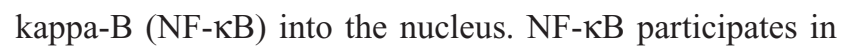
enhancing the expression of cytokines and other immunoregulatory mediators. ${ }^{16,17}$ This response is also present against endogenous stimuli (Figure 1).

In response to pattern detection, TLRs are involved in the activation of complement, coagulation, phagocytosis, and apoptosis functions. Alterations in the regulation of each of these processes can give rise to various pathological phenomena. ${ }^{18,19}$

\section{Toll like receptors}

The TLRs, members of the interleukin 1R superfamily, are transmembrane receptors with extracellular leucine-rich repeats and an intracellular signaling domain, and are found 


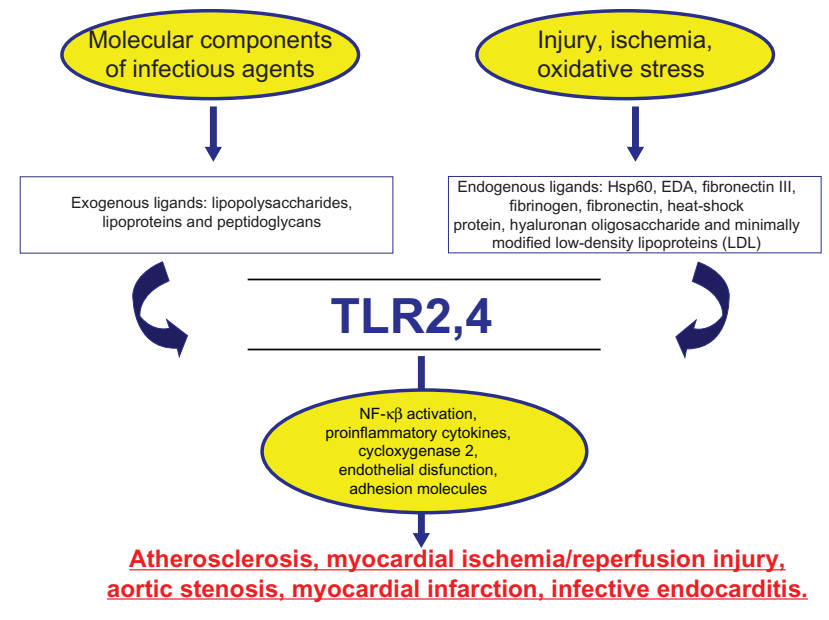

Figure I Diagram representing the possible endogenous and exogenous TLR activation pathways and the accompanying response.

Abbreviation: TLR, toll-like receptor.

in monocytes, macrophages and neutrophils. TLRs recognize microbial products (lipopolysaccharide [LPS], lipoproteins and peptidoglycans) and induce a signal in the affected cell through the p38 mitogen-activated protein kinase and NF-кB. ${ }^{20-22}$ To date, 11 TLRs have been identified, which recognize distinct pathogen-associated molecular patterns that have been evolutionarily conserved in specific classes of microbes (Table 1). These antigens include cell-wall components of gram-positive (bacterial lipoproteins and lipoteichoic acids, detected by TLR2) and gram-negative (LPS, detected by TLR4) bacteria. Recognition of LPS involves an LPS receptor complex, of which CD14 and the TLR4 are important components. ${ }^{23}$

Data suggests that the ability of certain individuals to respond properly to TLR ligands may be impaired by SNPs within TLR genes, resulting in an altered susceptibility to infection or inflammation. ${ }^{24}$ Polymorphisms of the TLR2 R753Q gene have been linked to variations in responses to Staphylococcal infection ${ }^{25}$ and are associated with a significantly increased risk of infective endocarditis, ${ }^{26}$ while el polymorphisms of $\mathrm{R} 677 \mathrm{~W}$ have been associated with an increased susceptibility to leprosy and tuberculosis in Asian populations. ${ }^{27}$ Two common mutations in the TLR4 gene have been described, TLR4 D299G and T399I. These mutations are reportedly linked to an increased risk of gram-negative bacterial infections and septic shock. ${ }^{23,28-30}$

\section{TLR signaling pathway}

The stimulation of the TLRs through intracellular signaling pathways activates various transcription factors that cause the production of inflammatory mediators. In addition to
Table I Different endogenous and exogenous components that recognize TLRs

\begin{tabular}{|c|c|}
\hline TLRs & Components \\
\hline \multirow[t]{13}{*}{ TLR2 (partnered with TLR6) } & Lipoproteins \\
\hline & Lipoteichoic acid \\
\hline & Modulin \\
\hline & Lipopeptides \\
\hline & MALP-2 \\
\hline & Glycolipids \\
\hline & GPI anchors \\
\hline & Peptidoglycan \\
\hline & Zymosan \\
\hline & Lipoarabinomannan \\
\hline & Viral porins \\
\hline & Viral hemagglutinin \\
\hline & Heat-shock proteins 60 and 70 \\
\hline \multirow[t]{11}{*}{ TLR4 } & LPS \\
\hline & Lipoteichoic acid \\
\hline & Mannan \\
\hline & Taxol \\
\hline & Heat-shock proteins 60 and 70 \\
\hline & Fibrinogen \\
\hline & Hyaluronan \\
\hline & Fibronectin EDA domain \\
\hline & Respiratory syncytial virus \\
\hline & fusion protein \\
\hline & Glycosylphospholipids \\
\hline
\end{tabular}

Abbreviations: TLR, toll-like receptor; LPS, lipopolysaccharide.

their pivotal role in host immune defense against invading pathogens, emerging evidence over the past ten years has demonstrated that TLRs appear capable of responding to stress, and modulating inflammation and tissue damage following noninfectious insults such as hypoxia, and ischemia in various tissues, ${ }^{31}$ including the lung, ${ }^{32}$ liver $^{33}$ or heart ${ }^{34-38}$ (Figure 1).

After joining their specific ligand, TLRs recruit and activate various downstream kinases such as interleukin receptor-associated kinase (IRAK)-1,4, tumor necrosis factor (TNF) receptor-associated factor (TRAF)-family memberassociated NF- $\mathrm{KB}$ activator-binding kinase 1 (TBK1) through a specific set of adaptors. TLR signaling can be divided into two general pathways, namely, MyD88- and Trif-dependent (or MyD88-independent) (Figure 2).

In the MyD88-dependent pathway, activated TLR4 recruits downstream IRAKs through the adapter proteins Mal and MyD88. Following a cascade of kinase activation this pathway ultimately leads to the activation of NF- $\mathrm{\kappa B}$ and the production of proinflammatory cytokine. ${ }^{39}$

In the Trif-dependent pathway, TLR4 signals through TRAM-Trif, resulting in TBK1 activation and a downstream stimulation of interferon regulatory factor 3 and production of interferon. ${ }^{40}$ 


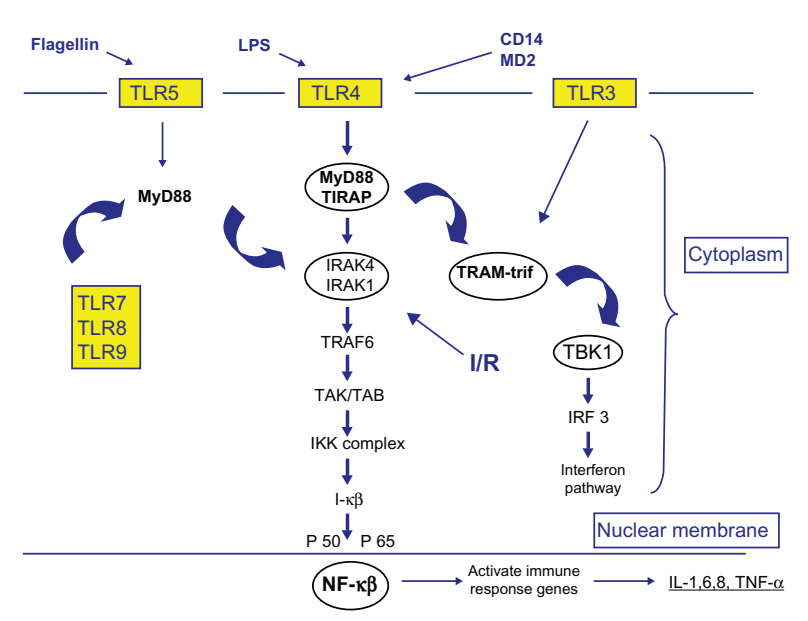

Figure 2 TLR4 signaling pathway.

Note: Activation sequence of each of the mediators that is involved and the molecules produced as a consequence of their activation and expression. ${ }^{68}$

Abbreviations: TLR, toll-like receptor; I/R, ischemic/reperfusion; NF- $\kappa B$, nuclear factor $\kappa B$; IL, interleukin; LPS, lipopolysaccharide; MAPK, mitogen-activated protein kinase; TRAM, TRIF-related adaptor molecule; TBKI, activator-binding kinase I; IRAK, interleukin receptor-associated kinase; TNF- $\alpha$, tumour necrosis factor- $\alpha$; TRAF, TNF receptor-associated factor.

In TLR2 signaling, TLR2 dimerizes with either TLR1 or TLR6. The heterodimers recruit and activate IRAK 4,1 via a Mal/MyD88-dependent mechanism and ultimately lead to the induction of cytokines. In the case of TLR2, this signaling pathway does not induce interferon production. All TLRs, with the exception of TLR3, signal through MyD88dependent pathways. ${ }^{41}$

In normal conditions TLRs are highly concentrated in the endothelium and heart, suggesting that TLRs are of functional importance in the cardiovascular system. ${ }^{42-44}$ Activation of most Toll-like receptors leads to the recruitment of the interleukin 1 receptor-associated kinase, and nuclear translocation of the latent cytoplasmic transcriptional regulator nuclear factor-kappa $\mathrm{B}(\mathrm{NF}-\mathrm{KB})$. Underscoring its central role in regulating the immune response, NF- $\kappa B$ is a critical mediator of several inflammatory pathways in addition to the Toll-like receptors. TLR2 and TLR4 bind bacterial cell wall components. TLR2 and TLR4 also respond to the endogenous ligands heat shock protein 60 (HSP60), HSP70, and Gp96, which may be released during necrotic cell death (Table 1). TLR3 recognizes polyI:C and doublestranded viral RNA, TLR5 binds gram-negative bacterial flagellin, TLR7 recognizes viral single-stranded RNA while TLR9 recognizes unmethylated $\mathrm{CpG}$ bacterial DNA (Table 2).

Following Toll-like receptor ligation, immune cells signal through NF- $\kappa B$ to produce the diverse cytokines and chemokines required for leukocyte activation and chemotaxis. Specialized tissues such as skeletal muscle, initially thought
Table 2 Different endogenous and exogenous components that recognize TLRs

\begin{tabular}{ll}
\hline TLRs & Components \\
\hline TLRI & - Bacterial triacyl lipopeptides \\
(partnered with TLR2) & - Certain proteins in parasites \\
TLR3 & - Viral double-stranded RNA \\
TLR5 & - Flagellin \\
TLR7/8 & - Viral single-stranded RNA \\
TLR9 & - Unmethylated CpG containing DNA \\
& - Hemozoin \\
TLRI0 & - Unknown \\
TLRII & - Profilin, a protein from Toxoplasmosis \\
& gondii \\
& - Not determined; present in \\
& uropathogenic bacteria \\
\hline
\end{tabular}

Abbreviations: TLR, toll-like receptor; $\mathrm{CPG}$, DNA oligonucleotides containing dinucleotide cytosine guanine.

to be bystanders in the immune response to pathogens, have recently been found to be active participants in response to Toll-like receptor ligation. In cardiomyocytes this response can give rise to inflammatory processes and intervene by diminishing contractility.

In mice, the occurrence of at least six of these receptors, namely TLR2, TLR3, TLR4, TLR5, TLR7 and TLR9, has been observed at cardiac level. ${ }^{45}$ It has been shown that a pathogenic ligand stimulation of TLR2, TLR4, TLR5 and TLR9 can lead to the activation of the NF-אB pathway and cardiomyocyte contractile dysfunction. ${ }^{45-47}$ The two receptors most studied at cardiac level are TLR2 and TLR4. ${ }^{47-52}$

In reference to their occurrence at cellular level, TLRs 2, 3, 4, 5 and 9 occur in arteries and in endothelial-origin cells, ${ }^{53,54}$ while arterial smooth muscle cells express mRNA for TLRs 3, 4, 5 and 9. ${ }^{54,55}$ Macrophages, the principal cell type within atheroma, express all of the TLRs and are responsive to all TLR ligands. ${ }^{54}$ Smooth muscle cells are responsive to TLR3, TLR4 and TLR9 ligands, whereas venous endothelial cells are responsive to TLRs 3, 4, 5 and 9 ligands. ${ }^{53,54,56}$

\section{Myocardial ischemic/reperfusion injury}

The innate immune system plays a fundamental role in the physiopathology of myocardial ischemic/reperfusion (I/R) injury. ${ }^{57}$ Furthermore, the physiological mechanisms that attempt to limit the inflammatory response, to promote survival of the myocardium, and to maintain homeostasis following cardiac $\mathrm{I} / \mathrm{R}$ remain unclear.

Ischemia is associated with hypoxia. Apoptosis has also been connected with this process, and therefore an increase 
in cell apoptosis is found in the ischemic-reperfused area, ${ }^{58}$ located mainly on the borders of necrotic areas. LPS seems to induce apoptosis in endothelial cells, ${ }^{59}$ while it has an antiapoptotic effect in monocytes, ${ }^{60}$ macrophages,${ }^{61}$ neutrophils, ${ }^{62}$ and cardiomyocytes ${ }^{63}$ This complements the explanation of certain processes that take place in $\mathrm{I} / \mathrm{R}$.

The TLR4-mediated NF- $\kappa \mathrm{B}$ activation pathway plays an important role in myocardial $\mathrm{I} / \mathrm{R}$ injury. Modulation of the TLR4-mediated signaling pathway or TLR4 deficiency is known to result in the protection against myocardial $\mathrm{I} / \mathrm{R}^{34,36,64} \mathrm{TLR} 2$ is also significant to these same processes of immune inflammatory response regulation. However, the mechanisms that regulate this response are not well known. Studies in mice with the inactive mutant TLR4, or genetically deficient for TLR $4,{ }^{36,65}$ TLR2 ${ }^{66}$ or MyD88, ${ }^{35}$ or pretreated with a TLR4 antagonist (eritoran) exhibited reduced myocardial infarction (MI) sizes compared with wild type or vehicletreated animals, respectively. ${ }^{67}$ This suggests that signaling through TLR2 and TLR4 modulates ischemic response at cardiac level.

LPS is known to induce cardiac dysfunction during endotoxemia in the adult mammalian heart. In wild type mice, at doses of $5 \mathrm{mg} / \mathrm{kg}$ and $25 \mathrm{mg} / \mathrm{kg}$, LPS induces significant left ventricle contractile dysfunction $(\% \mathrm{LV}$ fraccional shortening and myocardial velocity of LV circumferential shortening (Vcf)) through a TLR4-dependent mechanism. In contrast, there was no significant change in these parameters in the TLR-4-deficient mice when compared with diluent-treated control mice. ${ }^{51}$ Animal studies have demonstrated that administering sublethal doses of LPS confers a "preconditioning-like" effect. ${ }^{68}$ This effect is similar to that of ischemic preconditioning, or that of anesthesia-induced methods (inhaled anesthetics), protecting the heart from I/R injury. This effect is cancelled out by cycloheximide, a protein synthesis inhibitor that blocks translation elongation. ${ }^{69}$

Administering LPS provokes inducible nitric oxide synthase (iNOS) induction at cardiac level ${ }^{63,70}$ mediated by TLR4. ${ }^{51,63}$ Likewise, as with ischemic preconditioning, LPSinduced cardioprotection seems to be mediated by iNOS..$^{70,71}$

The data also seem to agree with in vitro observations that Akt, among other survival pathways, mediates a TLR4-mediated antiapoptotic benefit. ${ }^{63,72}$ In a study in mice, Wang et $\mathrm{al}^{73}$ showed that TLR4-MyD88 signaling confers potent cardiac protection against $\mathrm{I} / \mathrm{R}$ injury via iNOS- and sGC-dependent mechanisms. These data suggest that MyD88, but not Trif, signaling mediates the LPS-induced cardioprotection against I/R injury. Nevertheless, iNOS inhibition by $1400 \mathrm{~W}$ significantly lowers the cardioprotective effect of TLR4. Deficient TLR2 or TLR4 signaling in mice prevents adverse cardiac remodelling, resulting in preserved cardiac function and geometry after MI. ${ }^{37,38}$ Inhibition of TLRs may provide new therapeutic options after MI, a view which is supported by recent observations in TLR-knockout mice. ${ }^{74}$

In reference to TLR2, administration of TLR2 ligands protects the myocardium against I/R injury, and improves cardiac function and hemodynamics after I/R. However, this protection is lost in TLR2-deficient mice. It has been observed that blocking the PI3K/Akt signaling pathway impaired the TLR2 ligand-induced and PGN-induced cardioprotection. Modulation of TLR2-induced cardioprotection is known to be mediated through a PI3K/Akt-dependent mechanism. Treating mice with the TLR2 ligand significantly attenuated I/R-induced MI. ${ }^{11,75}$ Ischemic preconditioning has also been studied on other levels, such as at the cerebral level, ${ }^{76}$ where it was again found that the TLR2-specific ligand, Pam3CSK4, decreased I/R injury.

Another important fact is that NF- $\mathrm{KB}$ activation is inhibited in human mononuclear THP-1 cells pretreated with OPN-301 after P3C stimulation (selective ligand for TLR2). However, NF- $\mathrm{kB}$ activation does occur after lipopolysaccharide stimulation pretreated with OPN-301. OPN-301 selectively inhibits TLR2 signaling.

\section{Atherosclerosis and coronary artery disease}

The TLR signaling pathway plays a crucial role in the innate immune response, just as in the case of $\mathrm{I} / \mathrm{R}$. Previous studies $^{77-79}$ have shown how elevated circulating markers of systemic inflammatory status, such as TNF- $\alpha, \mathrm{C}$-reactive protein, IL-6, IL-8, and soluble vascular adhesion molecules (all related to the TLR signaling pathway) were also correlated with cardiovascular risk. Immunohistochemical studies have revealed that inflammatory processes are active within the developing plaque, with the demonstration that inflammatory gene products, such as IL-8, intercellular adhesion molecule (ICAM)-1, vascular cell adhesion molecule (VCAM)-1, E-selectin, and TNF- $\alpha$ were upregulated in atheroma plaque, as compared with healthy arterial areas or even with the control.

Evidence from diverse sources has suggested that TLRs can affect atherosclerosis in multiple ways, which might include both endogenous (MM-LDL, HSP60, EDA) and exogenous (that is, originating from pathogens) molecules among their cognate ligands. TLRs are capable of recognizing endogenous "danger signals", released during cell death. ${ }^{80}$ TLRs exert their inflammatory response through 
$\mathrm{NF}-\kappa \mathrm{B}$ translocation to the nucleus; the signaling pathway is superimposed on that, mediated in response to an external infectious agent.

It has been observed in mice, that specific deletion of either TLR2 or TLR4 also led to a significant reduction in the atherosclerosis burden. ${ }^{81-84}$ In arterial tissue obtained from Apo E-deficient mice, the levels of both TLR-2 and TLR-4 mRNA increased with time, and TLR-2 and TLR-4 expression on circulating monocytes increased after 40 weeks in Apo E-deficient mice compared with controls. ${ }^{85}$ A TLR-2 antagonist, Pam3CSK4, also enhanced lesion development in Apo E-deficient mice. ${ }^{86}$

TLR4 expression has also been seen to increase significantly in macrophages and endothelial cells in patients with arteriosclerosis. ${ }^{87}$ TLR4 ligation activates NF- $\kappa$ B, resulting in the expression of several inflammatory genes, and the proliferation of vascular smooth muscle cells. Kiechl et al ${ }^{88}$ observed that the TLR4 polymorphism Asp299Gly was associated with a decrease in atherosclerosis risk at femoral and carotid levels. The Bruneck study showed that allele asp 299-carrier patients had less progression in development of carotid atherosclerotic plaque. ${ }^{88}$

With respect to coronary pathology, a few months after the first large GWAS was published in early 2007, three independent GWAS for coronary artery disease were published from the Ottawa Heart Study, ${ }^{89}$ deCODE genetics, ${ }^{90}$ and from the Wellcome Trust Case-Control Consortium. ${ }^{91}$ The three studies concurred in locating the same significant loci on chromosome 9p21. Until that time, no other study had reported this association. Nevertheless, the SNPs identified were not associated with any of the traditional cardiovascular risk factors. Consequently, it appears that the genetic mechanism underlying the association signal is operating through a novel pathway. These results emphasise how difficult it is to link some of these genetic alterations with pathogenic mechanisms.

Other findings on coronary pathology, published by Ameziane et al, ${ }^{92}$ have been in agreement with those obtained in the Bruneck study. These authors observed that the allele Gly299 was associated with a reduction in the risk of acute coronary events, independently of the basal risk factors. Certain humeral mediators such as fibrinogen plasma and soluble VCAM-1 also showed lower concentrations in this patient group, just as pro-inflammatory cytokines, soluble adhesion molecules, and acute phase reactants. ${ }^{92}$ Similar findings have been reported by other authors such as Holloway et $\mathrm{al}^{93}$ and Kolek et al. ${ }^{94}$ The results, found in nonacute coronary pathology, showed that the presence of the allele Gly299 was not associated with a reduced time of plaque evolution. This differs from what has been observed in arteriopathy at the peripheral level, where plaque evolution was indeed found to slow down..$^{95,96}$

These alterations are related not only with the possibility of pathology development, but also with response to certain drugs. Damani et $\mathrm{a}^{17}$ showed the significance and clinical repercussions of the genomic component in the response to certain antiaggregants, such as clopidrogrel. In a recent study, it was observed how patients who were Gly299 allele carriers benefited from pravastatin treatment significantly more, in comparison with other groups. ${ }^{95}$

\section{Valvular heart disease}

As we have indicated, the TLR pathway modulates the inflammatory response, and these mechanisms are related to the development of arteriosclerosis. ${ }^{81,82}$ Pathological changes similar to those observed in arteriosclerosis are known to occur in the genesis of aortic stenosis (AS). AS is the most frequent valve pathology in the western world; although its occurrence was previously thought to be determined by passive mechanisms, it is now known to be an active process that can be considered an inflammatory process. ${ }^{98-101}$

The human aortic valve interstitial cell (HAVIC) has been implicated in the pathogenesis of AS. In response to proinflammatory stimulation via TLR2 and TLR4, the HAVIC phenotype changes from that of a myofibroblast to that of a bone-forming-like cell. ${ }^{102}$ Characteristics of this osteogenic phenotype include increased concentrations of the potent bone-forming protein, the osteogenic transcription factor, bone morphogenetic protein-2 (BMP-2), and Runx2, as well as increased concentration and activity of alkaline phosphatase. ${ }^{103-106}$ TLR4 generates cytoplasm signaling, leading to the phosphorylation of the IKK complex and mitogen-activated protein kinases, including p38 and JNK. Phosphorylation of IKK liberates bound NF- $\mathrm{BB}$ from the cytoplasm, and it then facilitates the production of proinflammatory mediators.

Meng et $\mathrm{al}^{103}$ showed that HAVICs express TLR2 and TLR4, and that PGN- or LPS-induced HAVIC stimulation leads to proinflammatory mediator expression, and production of factors related to the upregulation of osteogenesis. We can say that TLR2 and TLR4 are crucial in inflammatory phenomena at the level of the aortic valve, and in the development of stenosis. ${ }^{104}$

Song et al, in a study on native aortic valves, found that TLR4 mediated the ICAM-1 response to LPS in HAVICs. These results coincide with those observed by other authors, 
who found that ICAM-1 played an important role in leukocyte infiltration during inflammation. ${ }^{107,108}$ Microfilaments are associated with ICAM-1 after LPS stimulation, and also play an important role in regulating ICAM-1 expression and the influence of microfilaments on the cell surface. When the cells were treated with a TLR4-neutralising antibody or TLR4 siRNA, ICAM-1 induction by LPS was significantly attenuated. This reinforces the idea that TLR4 are crucially involved in mediating the ICAM-1 response to LPS in HAVICs. In valve pathology, it has been observed that cell exposure to viral as well as gram-negative bacteria patterns promotes TLR-mediated sustained inflammatory and pro-osteogenic responses, which could be relevant to the pathophysiology of degenerative AS.

In another area within valve pathology, our work group observed that the presence of TLR2 R753Q polymorphism was associated with a significantly increased risk of infective endocarditis, specifically with gram-positive bacterial infection. $^{26}$

\section{Applications of genomics in cardiovascular disease}

Genomics has made it possible to further our knowledge of the mechanisms regulating the development of specific pathologies. In the cardiovascular sphere, there has been an emphasis on genomic studies for the analysis of risk markers, and experts are attempting to incorporate results into the classic risk scales, in order to stratify patients for patient management. $77,109,110$

For a long time researchers have been working on designing molecules which allow them to modify the responses mediated by a damaging stimulus in which the immune response is involved. Said response is often exaggerated, and thereby causing an injury. It is known that these mechanisms are ultimately coded genetically and that, as indicated above, their alteration will lead to modification of the susceptibility to developing certain pathologies or the evolution of disease, as protein coding and its functionality will be affected.

Since the discovery of TLRs decades ago, much progress has been made in our understanding of the complex TLR signaling. The role of TLR agonists/antagonists is now being analyzed, in the hopes of decreasing the inflammatory response mediated by said signaling pathway. ${ }^{111}$ One example is OPN-301; this molecule was shown to inhibit TLR2 and reduce myocardial I/R injury, as well as preserve cardiac function and geometry in vivo. ${ }^{87}$ The same is true of specific TLR2 ligands such as PGN and Pam3CSK4, which improved cardiac function in mice after I/R injury, and therefore lowered its effects. ${ }^{75}$

Given the role of TLR2 in mediating ischemia-reperfusion injury, this molecule is attractive for testing in phase I clinical trials of patients with ischemic cardiomyopathy. In one study, AP177, a DNA aptamer identified by a SELEX (systematic evolution of ligands by exponential enrichment) screen, was found to bind to TLR and competitively antagonize TLR2 ligand binding, thereby inhibiting NF- $\kappa$ B activity and proinflammatory cytokine production. ${ }^{11,112}$

There are a number of strategies that have been undertaken to inhibit TLR4 activation. Eritoran (E5564), which reduces the binding of lipid-A (the biologically active part of the lipopolysaccharide molecule), reduced mortality by $6.4 \%$ compared with the placebo group in one phase II sepsis trial, and is currently undergoing evaluation in phase III sepsis trials (NCT00334828). Given that the pharmacodynamic profile of eritoran requires administration as a continuous infusion or by repeated intravenous injections, this TLR4 antagonist may not be practical in the treatment of chronic heart failure. However, it may be useful during myocardial inflammatory states or in the setting of acute coronary syndromes that lead to the development of heart failure. Alternative approaches have been to develop variations of lipid-A that bind TLR4 but these have reduced agonist activity (eg, CRX-527, lipidIVa). ${ }^{113}$ TAK-242 also targeted TLR4-dependent signaling, although the precise target is not known. ${ }^{114}$ Development of this compound was discontinued during a phase III sepsis clinical trial because the drug's profile did not meet the criteria required to support continued development, and not because of drug safety issues (NCT00633477). ${ }^{115}$ Ibudilast (AV411) is another TLR4 antagonist that suppresses proinflammatory cytokines such as TNF and IL-6, and may induce the anti-inflammatory cytokine IL-10; Ibudilast is undergoing phase II trials for opioid dependence (NCT00723177). Finally, OPN-401 is a viral protein-derived peptide that inhibits TLR4-dependent signaling and is also in preclinical development.

\section{Limitations}

It is important to remember that in genomics, the studies of cases and controls present significant limitations in terms of establishing associations, and their use in risk scales should consequently be accompanied by further, in-depth analysis. In addition, the results obtained in many cases present important variability with respect to the type of sample studied. In this sense, the GWAS represent an attempt to improve the results that have been already obtained. Genotyping of 
large data sets, and robust estimates that combine the results of different studies, are needed. The SNPs in the currently identified loci do not represent the full heritability estimate for the risk involved, so therefore it should be determined how newly emerging data from post-GWAS research could be incorporated into existing risk algorithms.

\section{Conclusion and future perspectives}

Various studies have analyzed the influence of genetic components, especially that of TLRs, on the development of cardiovascular pathology. The different findings lead us to believe that genomics has a relevant role in the genesis of these processes. The TLRs participate in the innate immune response system, but they also modulate the responses that arise in situations of tissue stress. There are discrepancies in some findings, which might be explained by differing study methods. The disparate findings also illustrate how complex and difficult it is to define the role of the TLRs as modulators of inflammation and tissue damage. In the future, it is possible that developments in genomics will enable us to better understand disease evolution and predisposition, as well as facilitate the design of new molecules that will improve the prognosis of some of these pathologies.

\section{Disclosure}

The authors declare no conflicts of interest.

\section{References}

1. Lander ES, Linton LM, Birren B, et al; for International Human Genome Sequencing Consortium. Initial sequencing and analysis of the human genome. Nature. 2001;409(6822):860-921.

2. Venter JC, Adams MD, Myers EW, et al. The sequence of the human genome. Science. 2001;291(5507):1304-1351.

3. International HapMap Consortium. The International HapMap Project. Nature. 2003;426(6968):789-796.

4. International HapMap Consortium, Frazer KA, Ballinger DG, Cox DR, et al. A second generation human haplotype map of over 3.1 million SNPs. Nature. 2007;449(7164):851-861.

5. International Human Genome Sequencing Consortium. Finishing the euchromatic sequence of the human genome. Nature. 2004;431(7011): 931-945.

6. Sachidanandam R, Weissman D, Schmidt SC, et al; for International SNP Map Working Group. A map of human genome sequence variation containing 1.42 million single nucleotide polymorphisms. Nature. 2001;409(6822):928-933.

7. International HapMap Consortium. A haplotype map of the human genome. Nature. 2005;437(7063):1299-1320.

8. Thanassoulis G, Vasan RS. Genetic cardiovascular risk prediction: will we get there? Circulation. 2010;122(22):2323-2334.

9. Medzhitov R, Preston-Hurlburt P, Janeway CA Jr. A human homologue of the Drosophila Toll protein signals activation of adaptive immunity. Nature. 1997;388(6640):394-397.

10. Aderem A, Ulevitch RJ. Toll-like receptors in the induction of the innate immune response. Nature. 2000;406(6797):782-787.
11. Ha T, Hu Y, Liu L, et al. TLR2 ligands induce cardioprotection against ischaemia/reperfusion injury through a PI3K/Akt-dependent mechanism. Cardiovasc Res. 2010;87(4):694-703.

12. Hindorff, LA, et al. 2010. A catalog of published genome-wide association studies. Available at www.genome.gov/gwastudies. Accessed August 6, 2012.

13. Burton PR, Clayton DG, Cardon LR, et al. Wellcome Trust Case Control Consortium. Genome-wide association study of 14,000 cases of seven common diseases and 3,000 shared controls. Nature. 2007; 447 (7145):661-678.

14. Shen GQ, Rao S, Martinelli N, et al. Association between four SNPs on chromosome 9p21 and myocardial infarction is replicated in an Italian population. J Hum Genet. 2008;53(2):144-150.

15. Lin E, Freedman JE, Beaulieu LM. Innate immunity and toll-like receptor antagonists: a potential role in the treatment of cardiovascular diseases. Cardiovasc Ther. 2009;27(2):117-123.

16. Arcaroli J, Fessler MB, Abraham E. Genetic polymorphisms and sepsis. Shock. 2005;24(4):300-312.

17. Akira S, Takeda K, Kaisho T. Toll-like receptors: critical proteins linking innate and acquired immunity. Nat Immunol. 2001;2(8):675-680.

18. Medzhitov R. Toll-like receptors and innate immunity. Nat Rev Immunol. 2001;1(2):135-145.

19. Napolitani G, Rinaldi A, Bertoni F, Sallusto F, Lanzavecchia A. Selected Toll-like receptor agonist combinations synergistically trigger a $\mathrm{T}$ helper type 1-polarizing program in dendritic cells. Nat Immunol. 2005;6(8): 769-776.

20. Beutler B. Tlr4: central component of the sole mammalian LPS sensor. Curr Opin Immunol. 2000;12(1):20-26.

21. Sabroe I, Jones EC, Usher LR, Whyte MK, Dower SK. Toll-like receptor (TLR) 2 and TLR4 in human peripheral blood granulocytes: a critical role for monocytes in leukocyte lipopolysaccharide responses. J Immunol. 2002;168(9):4701-4710.

22. Sabroe I, Parker LC, Wilson AG, Whyte MK, Dower SK. Toll-like receptors: their role in allergy and non-allergic inflammatory disease. Clin Exp Allergy. 2002;32(7):984-989.

23. Schröder NW, Schumann RR. Single nucleotide polymorphisms of Toll-like receptors and susceptibility to infectious disease. Lancet Infect Dis. 2005;5(3):156-164.

24. Cook DN, Pisetsky DS, Schwartz DA. Toll-like receptors in the pathogenesis of human disease. Nat Immunol. 2004;5(10): 975-979.

25. Lorenz E, Mira JP, Cornish KL, Arbour NC, Schwartz DA. A novel polymorphism in the toll-like receptor 2 gene and its potential association with staphylococcal infection. Infect Immun. 2000;68(11):6398-6401.

26. Bustamante J, Tamayo E, Flórez S, et al. Toll-like receptor 2 R753Q polymorphisms are associated with an increased risk of infective endocarditis. Rev Esp Cardiol. 2011;64(11):1056-1059. Spanish.

27. Kang TJ, Chae GT. Detection of Toll-like receptor 2 (TLR2) mutation in the lepromatous leprosy patients. FEMS Immunol Med Microbiol. 2001;31(1):53-58.

28. Montes AH, Asensi V, Alvarez V, et al. The Toll-like receptor 4 (Asp299Gly) polymorphism is a risk factor for Gram-negative and haematogenous osteomyelitis. Clin Exp Immunol. 2006;143(3): 404-413.

29. Agnese DM, Calvano JE, Hahm SJ, et al. Human toll-like receptor 4 mutations but not CD14 polymorphisms are associated with an increased risk of gram-negative infections. J Infect Dis. 2002;186(10): $1522-1525$

30. Lorenz E, Mira JP, Frees KL, Schwartz DA. Relevance of mutations in the TLR4 receptor in patients with gram-negative septic shock. Arch Intern Med. 2002;162(9):1028-1032.

31. Mollen KP, Anand RJ, Tsung A, Prince JM, Levy RM, Billiar TR. Emerging paradigm: toll-like receptor 4-sentinel for the detection of tissue damage. Shock. 2006;26(5):430-437.

32. Jiang D, Liang J, Fan J, et al. Regulation of lung injury and repair by Toll-like receptors and hyaluronan. Nat Med. 2005;11(11): 1173-1179. 
33. Prince JM, Levy RM, Yang R, et al. Toll-like receptor-4 signaling mediates hepatic injury and systemic inflammation in hemorrhagic shock. J Am Coll Surg. 2006;202(3):407-417.

34. Chong AJ, Shimamoto A, Hampton CR, et al. Toll-like receptor 4 mediates ischemia/reperfusion injury of the heart. JThorac Cardiovasc Surg. 2004;128(2):170-179.

35. Feng Y, Zhao H, Xu X, et al. Innate immune adaptor MyD88 mediates neutrophil recruitment and myocardial injury after ischemiareperfusion in mice. Am J Physiol Heart Circ Physiol. 2008;295(3): H1311-H1318.

36. Oyama J, Blais C Jr, Liu X, et al. Reduced myocardial ischemiareperfusion injury in toll-like receptor 4-deficient mice. Circulation. 2004;109(6):784-789.

37. Shishido T, Nozaki N, Yamaguchi S, et al. Toll-like receptor-2 modulates ventricular remodeling after myocardial infarction. Circulation. 2003;108(23):2905-2910.

38. Timmers L, Sluijter JP, van Keulen JK, et al. Toll-like receptor 4 mediates maladaptive left ventricular remodeling and impairs cardiac function after myocardial infarction. Circ Res. 2008;102(2): 257-264.

39. Fitzgerald KA, Palsson-McDermott EM, Bowie AG, et al. Mal (MyD88adapter-like) is required for Toll-like receptor-4 signal transduction. Nature. 2001;413(6851):78-83.

40. Yamamoto M, Sato S, Hemmi H, et al. Role of adaptor TRIF in the MyD88-independent toll-like receptor signaling pathway. Science. 2003;301(5633):640-643.

41. Hoebe K, Du X, Georgel P, et al. Identification of Lps2 as a key transducer of MyD88-independent TIR signalling. Nature. August 14 2003;424(6950):743-748.

42. Visintin A, Mazzoni A, Spitzer JH, Wyllie DH, Dower SK, Segal DM. Regulation of Toll-like receptors in human monocytes and dendritic cells. J Immunol. 2001;166(1):249-255.

43. Zarember KA, Godowski PJ. Tissue expression of human Toll-like receptors and differential regulation of Toll-like receptor mRNAs in leukocytes in response to microbes, their products, and cytokines. J Immunol. 2002;168(2):554-561.

44. Aliprantis AO, Yang RB, Weiss DS, Godowski P, Zychlinsky A. The apoptotic signaling pathway activated by Toll-like receptor-2. EMBOJ. July 3, 2000;19(13):3325-3336.

45. Boyd JH, Mathur S, Wang Y, Bateman RM, Walley KR. Toll-like receptor stimulation in cardiomyoctes decreases contractility and initiates an NF-kappaB dependent inflammatory response. Cardiovasc Res. 2006;72(3):384-393.

46. Knuefermann P, Schwederski M, Velten M, et al. Bacterial DNA induces myocardial inflammation and reduces cardiomyocyte contractility: role of toll-like receptor 9. Cardiovasc Res. 2008;78(1):26-35.

47. Zhu X, Bagchi A, Zhao H, et al. Toll-like receptor 2 activation by bacterial peptidoglycan-associated lipoprotein activates cardiomyocyte inflammation and contractile dysfunction. Crit Care Med. 2007;35(3) 886-892.

48. Frantz S, Kobzik L, Kim YD, et al. Toll4 (TLR4) expression in cardiac myocytes in normal and failing myocardium. J Clin Invest. 1999;104(3): 271-280.

49. Knuefermann P, Nemoto S, Misra A, et al. CD14-deficient mice are protected against lipopolysaccharide-induced cardiac inflammation and left ventricular dysfunction. Circulation. 2002;106(20): 2608-2615.

50. Knuefermann P, Sakata Y, Baker JS, et al. Toll-like receptor 2 mediates Staphylococcus aureus-induced myocardial dysfunction and cytokine production in the heart. Circulation. 2004;110(24): 3693-3698.

51. Nemoto S, Vallejo JG, Knuefermann P, et al. Escherichia coli LPSinduced LV dysfunction: role of toll-like receptor-4 in the adult heart. Am J Physiol Heart Circ Physiol. 2002;282(6):H2316-H2323.

52. Frantz S, Ertl G, Bauersachs J. Mechanisms of disease: Toll-like receptors in cardiovascular disease. Nat Clin Pract Cardiovasc Med. 2007;4(8):444-454.
53. Dunzendorfer S, Lee HK, Tobias PS. Flow-dependent regulation of endothelial Toll-like receptor 2 expression through inhibition of SP1 activity. Circ Res. 2004;95(7):684-691.

54. Erridge C, Burdess A, Jackson AJ, et al. Vascular cell responsiveness to Toll-like receptor ligands in carotid atheroma. Eur J Clin Invest. 2008;38(10):713-720.

55. Yang X, Murthy V, Schultz K, Tatro JB, Fitzgerald KA, Beasley D. Toll-like receptor 3 signaling evokes a proinflammatory and proliferative phenotype in human vascular smooth muscle cells. Am J Physiol Heart Circ Physiol. 2006;291(5):H2334-H2343.

56. Erridge C, Spickett CM, Webb DJ. Non-enterobacterial endotoxins stimulate human coronary artery but not venous endothelial cell activation via Toll-like receptor 2. Cardiovasc Res. 2007;73(1):181-189.

57. Linde A, Mosier D, Blecha F, Melgarejo T. Innate immunity and inflammation - New frontiers in comparative cardiovascular pathology. Cardiovasc Res. 2007;73(1):26-36.

58. Gottlieb RA, Burleson KO, Kloner RA, Babior BM, Engler RL. Reperfusion injury induces apoptosis in rabbit cardiomyocytes. J Clin Invest. 1994;94(4):1621-1628.

59. Choi KB, Wong F, Harlan JM, Chaudhary PM, Hood L, Karsan A. Lipopolysaccharide mediates endothelial apoptosis by a FADDdependent pathway. J Biol Chem. 1998;273(32):20185-20188.

60. Manna SK, Aggarwal BB. Lipopolysaccharide inhibits TNF-induced apoptosis: role of nuclear factor-kappaB activation and reactive oxygen intermediates. J Immunol. 1999;162(3):1510-1518.

61. Lombardo E, Alvarez-Barrientos A, Maroto B, Boscá L, Knaus UG. TLR4-mediated survival of macrophages is MyD88 dependent and requires TNF-alpha autocrine signalling. J Immunol. 2007;178(6): 3731-3739.

62. Ward C, Murray J, Clugston A, Dransfield I, Haslett C, Rossi AG. Interleukin-10 inhibits lipopolysaccharide-induced survival and extracellular signal-regulated kinase activation in human neutrophils. Eur J Immunol. 2005;35(9):2728-2737.

63. Zhu X, Zhao H, Graveline AR, et al. MyD88 and NOS2 are essential for toll-like receptor 4-mediated survival effect in cardiomyocytes. Am J Physiol Heart Circ Physiol. 2006;291(4):H1900-H1909.

64. Li C, Ha T, Kelley J, et al. Modulating Toll-like receptor mediated signaling by (1-->3)-beta-D-glucan rapidly induces cardioprotection. Cardiovasc Res. 2004;61(3):538-547.

65. Kim SC, Ghanem A, Stapel H, et al. Toll-like receptor 4 deficiency: smaller infarcts, but no gain in function. BMC Physiol. 2007; 7:5.

66. Favre J, Musette P, Douin-Echinard V, et al. Toll-like receptors 2-deficient mice are protected against postischemic coronary endothelial dysfunction. Arterioscler Thromb Vasc Biol. 2007;27(5):1064-1071.

67. Shimamoto A, Chong AJ, Yada M, et al. Inhibition of Toll-like receptor 4 with eritoran attenuates myocardial ischemia-reperfusion injury. Circulation. July 4, 2006;114(Suppl 1):I270-I274.

68. Chao W. Toll-like receptor signaling: a critical modulator of cell survival and ischemic injury in the heart. Am J Physiol Heart Circ Physiol. 2009; 296(1):H1-H12.

69. Meng X, Ao L, Brown JM, et al. LPS induces late cardiac functional protection against ischemia independent of cardiac and circulating TNF-alpha. Am J Physiol. 1997;273(4 Pt 2):H1894-H1902.

70. Wang Y, Guo Y, Zhang SX, et al. Ischemic preconditioning upregulates inducible nitric oxide synthase in cardiac myocyte. J Mol Cell Cardiol. 2002;34(1):5-15.

71. Ha T, Hua F, Liu X, et al. Lipopolysaccharide-induced myocardial protection against ischaemia/reperfusion injury is mediated through a PI3K/Akt-dependent mechanism. Cardiovasc Res. 2008;78(3): 546-553.

72. Chao W, Shen Y, Zhu X, et al. Lipopolysaccharide improves cardiomyocyte survival and function after serum deprivation. J Biol Chem. 2005;280(23):21997-22005.

73. Wang E, Feng Y, Zhang M, et al. Toll-like receptor 4 signaling confers cardiac protection against ischemic injury via inducible nitric oxide synthase- and soluble guanylate cyclase-dependent mechanisms. Anesthesiology. 2011;114(3):603-613. 
74. Arslan F, Smeets MB, O’Neill LA, et al. Myocardial ischemia/reperfusion injury is mediated by leukocytic toll-like receptor-2 and reduced by systemic administration of a novel anti-toll-like receptor-2 antibody. Circulation. 2010;121(1):80-90.

75. Dong JW, Vallejo JG, Tzeng HP, Thomas JA, Mann DL. Innate immunity mediates myocardial preconditioning through Toll-like receptor 2 and TIRAP-dependent signaling pathways. Am J Physiol Heart Circ Physiol. 2010;298(3):H1079-H1087.

76. Hua F, Ma J, Ha T, et al. Preconditioning with a TLR2 specific ligand increases resistance to cerebral ischemia/reperfusion injury. J Neuroimmunol. 2008;199(1-2):75-82.

77. Ikonomidis I, Stamatelopoulos K, Lekakis J, Vamvakou GD, Kremastinos DT. Inflammatory and non-invasive vascular markers: the multimarker approach for risk stratification in coronary artery disease. Atherosclerosis. 2008;199(1):3-11.

78. Davies MJ, Gordon JL, Gearing AJ, et al. The expression of the adhesion molecules ICAM-1, VCAM-1, PECAM, and E-selectin in human atherosclerosis. J Pathol. 1993;171(3):223-229.

79. Barath P, Fishbein MC, Cao J, Berenson J, Helfant RH, Forrester JS. Detection and localization of tumor necrosis factor in human atheroma. Am J Cardiol. 1990;65(5):297-302.

80. Matzinger P. The danger model: a renewed sense of self. Science. 2002;296(5566):301-305

81. Michelsen KS, Wong MH, Shah PK, et al. Lack of Toll-like receptor 4 or myeloid differentiation factor 88 reduces atherosclerosis and alters plaque phenotype in mice deficient in apolipoprotein E. Proc Natl Acad Sci U S A. 2004;101(29):10679-10684.

82. Mullick AE, Tobias PS, Curtiss LK. Modulation of atherosclerosis in mice by Toll-like receptor 2. J Clin Invest. 2005;115(11): 3149-3156.

83. Liu X, Ukai T, Yumoto H, et al. Toll-like receptor 2 plays a critical role in the progression of atherosclerosis that is independent of dietary lipids. Atherosclerosis. 2008;196(1):146-154.

84. Madan M, Amar S. Toll-like receptor-2 mediates diet and/or pathogen associated atherosclerosis: proteomic findings. PLoS One. 2008;3(9): e3204.

85. Schoneveld AH, Hoefer I, Sluijter JP, Laman JD, de Kleijn DP, Pasterkamp G. Atherosclerotic lesion development and Toll like receptor 2 and 4 responsiveness. Atherosclerosis. 2008;197(1): 95-104.

86. Schoneveld AH, Oude Nijhuis MM, van Middelaar B, Laman JD, de Kleijn DP, Pasterkamp G. Toll-like receptor 2 stimulation induces intimal hyperplasia and atherosclerotic lesion development. Cardiovasc Res. 2005;66(1):162-169.

87. Edfeldt K, Swedenborg J, Hansson GK, Yan ZQ. Expression of toll-like receptors in human atherosclerotic lesions: a possible pathway for plaque activation. Circulation. 2002;105(10):1158-1161.

88. Kiechl S, Lorenz E, Reindl M, et al. Toll-like receptor 4 polymorphisms and atherogenesis. N Engl J Med. 2002;347(3):185-192.

89. McPherson R, Pertsemlidis A, Kavaslar N, et al. A common allele on chromosome 9 associated with coronary heart disease. Science. 2007; 316(5830):1488-1491.

90. Helgadottir A, Thorleifsson G, Manolescu A, et al. A common variant on chromosome 9p21 affects the risk of myocardial infarction. Science. 2007;316(5830):1491-1493.

91. Samani NJ, Erdmann J, Hall AS, et al; for WTCCC and the Cardiogenics Consortium. Genomewide association analysis of coronary artery disease. N Engl J Med. 2007;357(5):443-453.

92. Ameziane N, Beillat T, Verpillat P, et al. Association of the Toll-like receptor 4 gene Asp299Gly polymorphism with acute coronary events. Arterioscler Thromb Vasc Biol. 2003;23(12):e61-e64.

93. Holloway JW, Yang IA, Ye S. Variation in the toll-like receptor 4 gene and susceptibility to myocardial infarction. Pharmacogenet Genomics. 2005;15(1):15-21.

94. Kolek MJ, Carlquist JF, Muhlestein JB, et al. Toll-like receptor 4 gene Asp299Gly polymorphism is associated with reductions in vascular inflammation, angiographic coronary artery disease, and clinical diabetes. Am Heart J. 2004;148(6):1034-1040.
95. Boekholdt SM, Agema WR, Peters RJ, et al; for REgression GRowth Evaluation Statin Study Group. Variants of toll-like receptor 4 modify the efficacy of statin therapy and the risk of cardiovascular events. Circulation. 2003;107(19):2416-2421.

96. Yang IA, Holloway JW, Ye S; for Southampton Atherosclerosis Study (SAS) Group. TLR4 Asp299Gly polymorphism is not associated with coronary artery stenosis. Atherosclerosis. 2003;170(1):187-190.

97. Damani SB, Topol EJ. Emerging genomic applications in coronary artery disease. JACC Cardiovasc Interv. 2011;4(5):473-482.

98. Rajamannan NM, Subramaniam M, Rickard D, et al. Human aortic valve calcification is associated with an osteoblast phenotype. Circulation. 2003;107(17):2181-2184.

99. Anger T, Carson W, Weyand M, Daniel WG, Hoeher M, Garlichs CD. Atherosclerotic inflammation triggers osteogenic bone transformation in calcified and stenotic human aortic valves: still a matter of debate. Exp Mol Pathol. 2009;86(1):10-17.

100. Mohler ER 3rd, Gannon F, Reynolds C, Zimmerman R, Keane MG, Kaplan FS. Bone formation and inflammation in cardiac valves. Circulation. 2001;103(11):1522-1528.

101. Kaden JJ, Dempfle CE, Grobholz R, et al. Inflammatory regulation of extracellular matrix remodeling in calcific aortic valve stenosis. Cardiovasc Pathol. 2005;14(2):80-87.

102. Kaden JJ, Kiliç R, Sarikoç A, et al. Tumor necrosis factor alpha promotes an osteoblast-like phenotype in human aortic valve myofibroblasts: a potential regulatory mechanism of valvular calcification. Int $\mathrm{J} \mathrm{Mol}$ Med. 2005;16(5):869-872.

103. Meng X, Ao L, Song Y, et al. Expression of functional Toll-like receptors 2 and 4 in human aortic valve interstitial cells: potential roles in aortic valve inflammation and stenosis. Am J Physiol Cell Physiol. 2008;294(1):C29-C35.

104. Yang X, Fullerton DA, Su X, Ao L, Cleveland JC Jr, Meng X. Pro-osteogenic phenotype of human aortic valve interstitial cells is associated with higher levels of Toll-like receptors 2 and 4 and enhanced expression of bone morphogenetic protein 2. J Am Coll Cardiol. 2009;53(6):491-500.

105. Babu AN, Meng X, Zou N, et al. Lipopolysaccharide stimulation of human aortic valve interstitial cells activates inflammation and osteogenesis. Ann Thorac Surg. 2008;86(1):71-76.

106. Yang X, Meng X, Su X, et al. Bone morphogenic protein 2 induces Runx 2 and osteopontin expression in human aortic valve interstitial cells: role of Smad1 and extracellular signal-regulated kinase 1/2. J Thorac Cardiovasc Surg. 2009;138(4):1008-1015.

107. Song Y, Fullerton DA, Mauchley D, et al. Microfilaments facilitate TLR4-mediated ICAM-1 expression in human aortic valve interstitial cells. J Surg Res. 2011;166(1):52-58.

108. van de Stolpe A, van der Saag PT. Intercellular adhesion molecule-1. J Mol Med (Berl). 1996;74(1):13-33.

109. Millán J, Hewlett L, Glyn M, Toomre D, Clark P, Ridley AJ. Lymphocyte transcellular migration occurs through recruitment of endothelial ICAM-1 to caveola- and F-actin-rich domains. Nat Cell Biol. 2006;8(2):113-123.

110. Humphries SE, Drenos F, Ken-Dror G, Talmud PJ. Coronary heart disease risk prediction in the era of genome-wide association studies: current status and what the future holds. Circulation. 2010;121(20): 2235-2248.

111. Wickelgren I. Immunology. Targeting the tolls. Science. 2006; 312(5771):184-187.

112. Hennessy EJ, Parker AE, O’Neill LA. Targeting Toll-like receptors: emerging therapeutics? Nat Rev Drug Discov. 2010;9(4): 293-307.

113. Erridge $\mathrm{C}$. The roles of Toll-like receptors in atherosclerosis. J Innate Immun. 2009;4:340-349.

114. Rice TW, Wheeler AP, Bernard GR, et al. A randomized, double-blind, placebo-controlled trial of TAK-242 for the treatment of severe sepsis. Crit Care Med. 2010;38:1685-1694.

115. Hutchinson MR, Lewis SS, Coats BD, et al. Reduction of opioid withdrawal and potentiation of acute opioid analgesia by systemic AV411 (ibudilast). Brain Behav Immun. 2009;23:240-50. 
International Journal of General Medicine

Dovepress

\section{Publish your work in this journal}

The International Journal of General Medicine is an international, peer-reviewed open-access journal that focuses on general and internal medicine, pathogenesis, epidemiology, diagnosis, monitoring and treatment protocols. The journal is characterized by the rapid reporting of reviews, original research and clinical studies across all disease areas.
A key focus is the elucidation of disease processes and management protocols resulting in improved outcomes for the patient. The manuscript management system is completely online and includes a very quick and fair peer-review system. Visit http://www.dovepress.com/ testimonials.php to read real quotes from published authors.

Submit your manuscript here: http://www.dovepress.com/international-journal-of-general-medicine-journal 